\title{
NEUTRON AND X-RAY SCATTERING STUDIES OF THE METALLURGICAL CONDITION AND RESIDUAL STRESSES IN WELDALITE WELDS
}

\author{
S. Spooner ${ }^{1}$ and E. B. S. Pardue ${ }^{2}$ \\ 1Oak Ridge National Laboratory* \\ Oak Ridge, TN 37831 \\ 2 Technology for Energy Corporation \\ Knoxville, TN 37932
}

\begin{abstract}
Neutron and $\mathrm{x}$-ray scattering methods of residual stress measurement were applied to plasma arc welds made in aluminum-lithium alloy test panels as part of an evaluation of materials for use in welded structures. In the course of these studies discrepancies between X-ray and neutron results from the heat affected zone (HAZ) of the weld were found. Texture changes and recovery from the cold work, indicated in peak widths, were found in the HAZ as well. The consideration of $x$-ray and neutron results leads to the conclusion that there is a change in solute composition which modifies the d-spacings in the HAZ which affects the neutron diffraction determination of residual stresses. The composition changes give the appearance of significant compressive strains in the HAZ. This effect and sharp gradients in the texture give severe anomalies in the neutron measurement of residual stress. The use of combined x-ray and neutron techniques and the solution to the minimizing of the neutron diffraction anomalies are discussed.
\end{abstract}

\section{INTRODUCTION}

Weldalite is a lithium-containing aluminum alloy which is being considered for aerospace applications because its favorable strength-to-weight ratio. Sucessful welding of this alloy depends on the control of the metallurgical condition and residual stresses in the heat affected zone (HAZ) and for this reason x-ray and neutron measurements of residual stress were undertaken in a study of plasma arc welded test panels of 2195 type Weldalite alloy. The alloy plate is cold-rolled and the residual stresses arising from welding distorts the test panels. While the $\mathrm{x}$-ray method gives the residual stresses at the surface, the neutron method is expected to characterize the residual stresses through the thickness of the material because the neutrons readily penetrate the material. The extrapolation of the neutron results to the surface should result in biaxial residual stress results in agreement with $\mathrm{x}$-ray measurements. The observed discrepancies, their causes and the resolution of differences between the $\mathrm{x}$-ray and neutron results are described in this paper.

\section{EXPERIMENTAL}

The $x$-ray residual stresses were measured using the $\sin ^{2} y$ technique (1) assuming a biaxial stress state. The basic equation,

$$
\sigma_{\phi \psi}=\frac{E}{(1+v)} \frac{1}{\sin ^{2} \psi} \frac{\left(d_{\psi=\psi}-d_{\psi=0}\right)}{d_{0}}
$$

approximates the unstressed d-spacing ( $\left.d_{0}\right)$ by the intercept value of the $d$-spacing versus $\sin ^{2} y$ curve. Copper $\mathrm{K}_{\mathrm{a}}$ radiation $(0.1542 \mathrm{~nm}$ ) was used to difrract the $(511,333)$ planes in aluminum

* Managed by Lockheed Martin Energy Systems, under contract

DE-AC05-840R21400 for the U.S. Department of Energy.

The submitted manuscript has been authored by a contractor of the U.S. Government under contract Ho. DEACO5-840R2 1400. Accordingly. the U.S. DISTRIBUIION OF THS DOCUMENT IS UNLWWIFD DISTRIBUIION OF THS DOCUMENT IS UNLLWIIED DISTRIBUTHNN OF THS DOCUMENT IS UNLLWIIED purposes." 
at approximately $164^{\circ} 2 \mathrm{q}$. The elastic compliance used to convert strain to stress was $1.62810^{-5}$ $\mathrm{MPa}-1$. Ten to sixteen y tilts between $0^{\circ}$ and $45^{\circ}$ were employed along with four degrees oscillation to minimize the oscillatory behavior commonly seen in textured material.

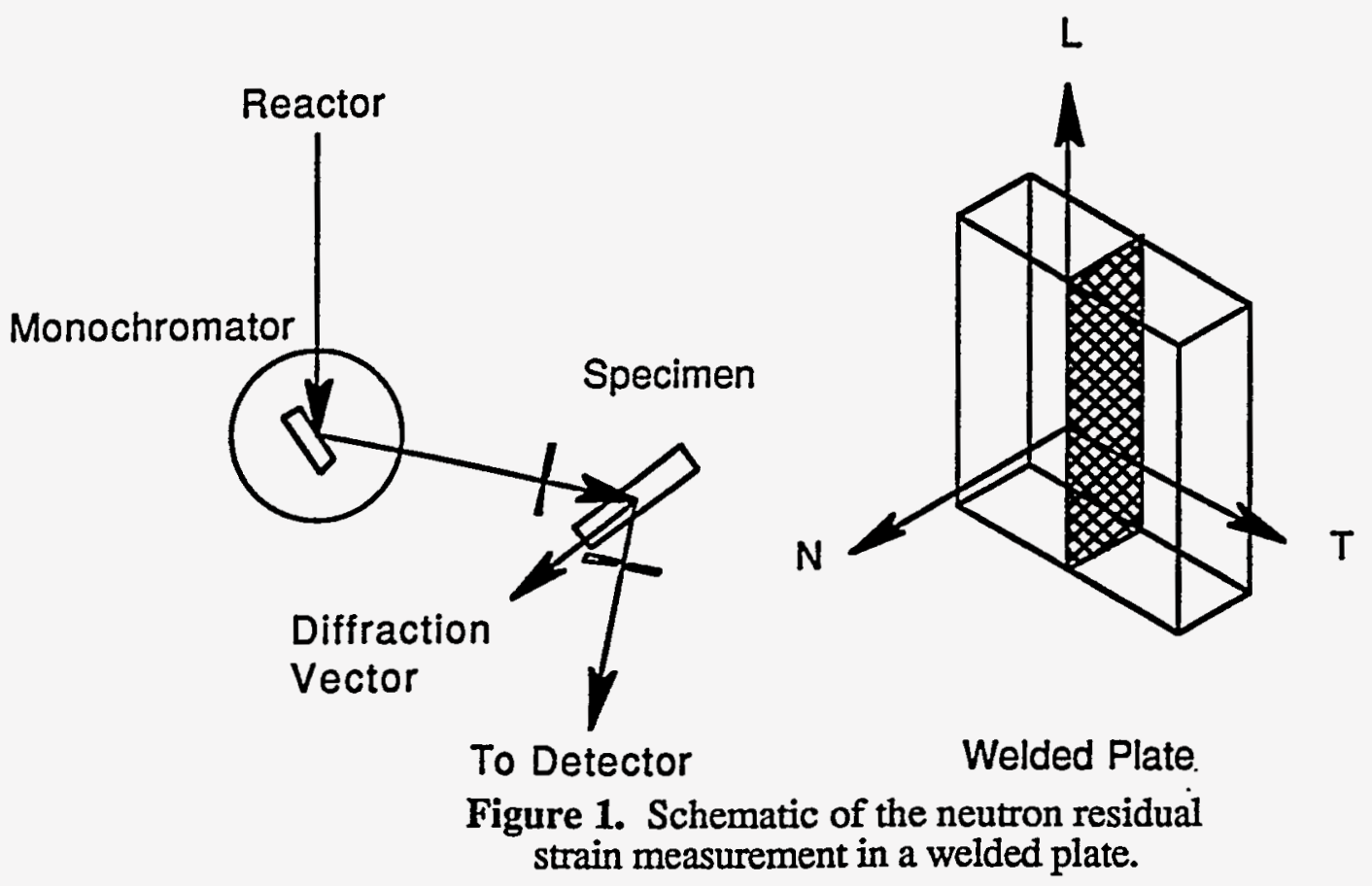

In the neutron method (2), as in the X-ray method, diffraction is used to measure the dspacing of a selected ( $\mathrm{d}_{\mathrm{hkl}}$ ) plane. The change in the d-spacing from a stress-free $\mathrm{d}$-spacing gives the strain in the direction of the normal to the diffracting planes. The strain may be calculated from

$$
\varepsilon=\frac{\delta d_{h k l}}{\delta d_{h k l}}=\left(\frac{\sin \left(\theta_{0}\right)}{\sin (\theta)}-1\right)
$$

where $q 0$ is the stress-free Bragg angle and $q$ is the observed Bragg angle. The gauge volume is defined by an incident beam collimator and the scattering collimator as shown in Figure 1 . The stress is calculated from the three orthogonal strain components which are assumed to be along the principal axes of the strain ellipsoid at the point of measurement in the sample. The Young's modulus, $\mathrm{E}$, and the Poisson ratio, $\mathrm{n}$, for the bulk are used in the following equations

$$
\sigma_{i}=\frac{E}{(1-v)}\left(\varepsilon_{i}+\frac{v}{(1-2 v)}\left[\varepsilon_{i}+\varepsilon_{j}+\varepsilon_{k}\right]\right)
$$

where $i=1,2,3$ for the three stress and strain components. For the measurement of residual stress in a welded plate, the assumption is made that the principal axes of the strain tensor are along the weld line, perpendicular to the weld line and in the plate and normal to the plate as shown in Figure 1.

The neutron measurements were made on the HB-2 spectrometer which was modified by the addition of collimators, sample positioners, and a linear position-sensitive proportional counter. A description of the experimental details for the study of a welded plate on a similar diffractometer is given in Ref. 3. A neutron beam monochromated by reflection at $90^{\circ}$ from the (110) plane of a beryllium crystal giving a wavelength of $1.61 \AA$ was used in these experiments. The (311) reflection was used in the strain measurements. 
The weld test panels were $305 \mathrm{~mm}$ by $610 \mathrm{~mm}$ by $5 \mathrm{~mm}$. The base material was cold rolled 2195-T87 Weldalite alloy and the weld was made with two passes; the first was an autogenous weld using variable phase plasma arc process, the second a cover pass using 2319 alloy filler wire.

\section{RESULTS AND DISCUSSION}

Microstructural changes in the HAZ are indicated by the variation in diffraction peak intensity and peak breadth. In Figure 2 the neutron scattering intensity and the peak breadths for both $\mathrm{x}$-ray and neutron diffraction peaks are shown as a function of the distance from the weld center. The narrowing peak breadth in the HAZ is attributed to the removal of microstrains and

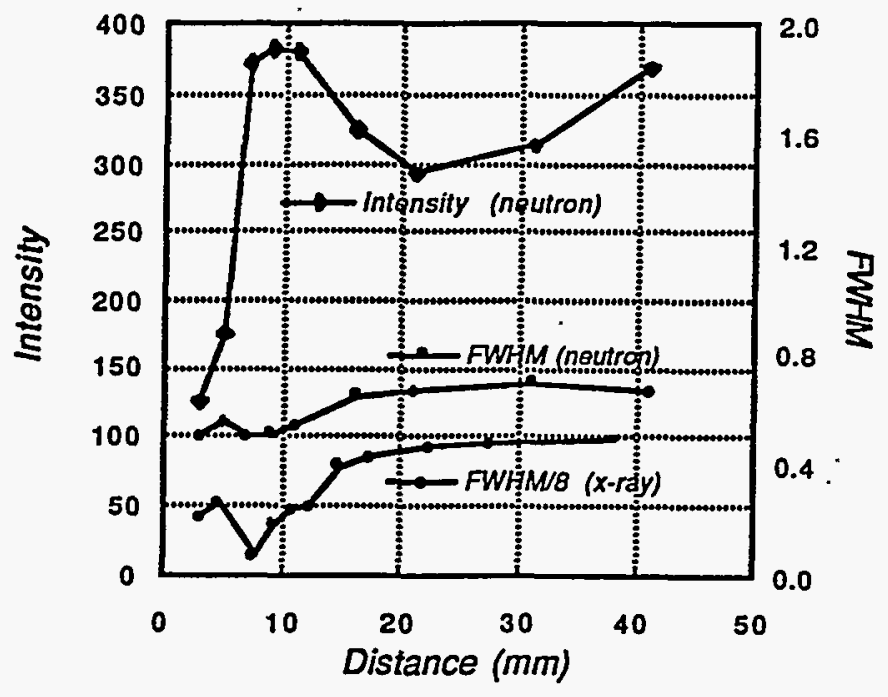

Figure 2. Variation in intensity and peak widths indicate microstructural changes in the HAZ. Note that the $x$-ray peak widths are divided by 8 .

subgrain growth during the brief recovery process which happens during welding. The two-fold intensity change in the diffraction peak, which was used to measure the normal strain component, is attributed to small changes in the very sharp texture during the same transient annealing.

The degree of texturing in the base metal was evaluated by the measurement of diffracted intensity as a function of rotation about an axis parallel to the weld line in the plate. Figure 3 shows how sharply the (311) Bragg intensity varies with rotation. There are 5 curves corresponding to different depths for the sampling point in the plate. The rotation angle corresponding to the orientation for measurement of the transverse (T) and normal (N) strain components is indicated by arrows.

\section{DISCLAIMER}

This report was prepared as an account of work sponsored by an agency of the United States Government. Neither the United States Government nor any agency thereof, nor any of their employees, makes any warranty, express or implied, or assumes any legal liability or responsibility for the accuracy, completeness, or usefulness of any information, apparatus, product, or process disclosed, or represents that its use would not infringe privately owned rights. Reference herein to any specific commercial product, process, or service by trade name, trademark, manufacturer, or otherwise does not necessarily constitute or imply its endorsement, recommendation, or favoring by the United States Government or any agency thereof. The views and opinions of authors expressed herein do not necessarily state or reflect those of the United States Government or any agency thereof. 


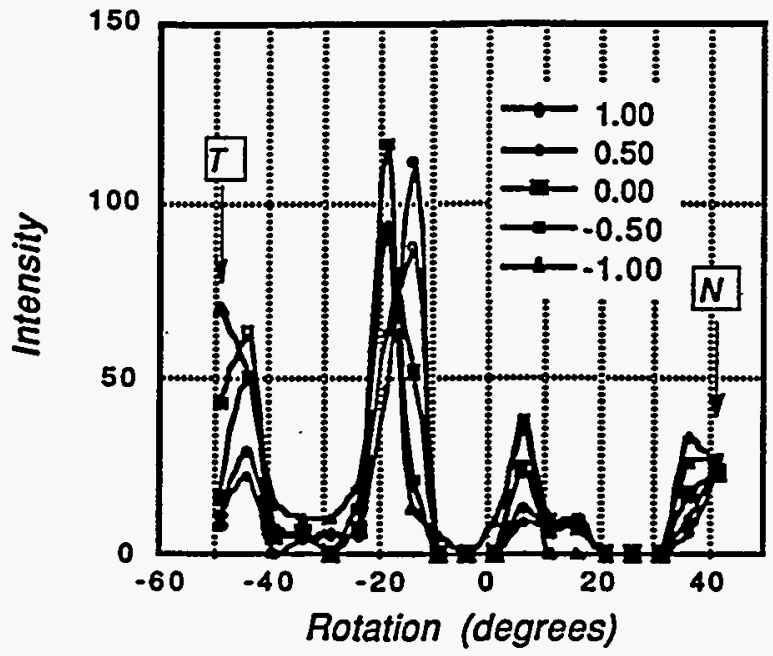

Figure 3. Sharp (311) peak intensity variation with rotation indicates a high degree of texture in the base metal of the welded plate.

The influence of texture and texture gradients on the determination of strain is demonstrated in an experiment with a small sample of the base metal in which a through-thickness scan of the Bragg peak was made. The beam collimators defined a tall thin diffracting gauge volume with the long axis parallel to the plate surface. The measurement of the intensity and peak position are shown in Figure 4. The strain (referenced to a d-spacing near the center) appears to go compressive as the position approaches the sample surface. The observation is believed to be an alignment artifact where the gauge volume is not uniformly populated by diffracting grains. This apparent shift in strain can be calculated by determining the shift in diffracted intensity arising from the effect of displacing the center of gravity of the gauge volume off the axis of the spectrometer; both sample displacement and neutron wavelength distribution contribute to the artifact. In this case, there is a sharp change in intensity due to rapid variation in the grain texture as a function of depth in the plate. 


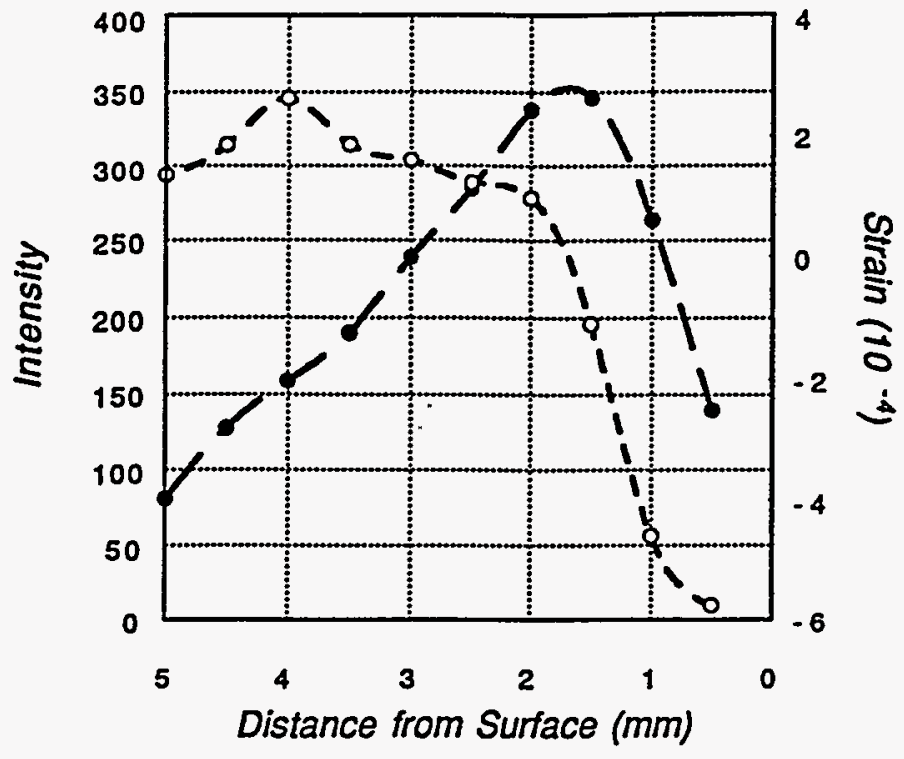

Figure 4. Through-thickness variation of intensity (filled circles) is associated with a strain (open circles) artifact.

The discrepancy between $x$-ray and neutron residual stress measurements is shown in Figure 5 where the transverse stress is shown to be nearly zero from the $x$-ray determination and is stongly compressive $(-300 \mathrm{MPa})$ from the neutron determination. The normal stress is expected to be small since the plane stress condition should apply to the plate under study and clearly this is not the case for the stresses calculated from uncorrected neutron strains. A correction was applied to the calculation of stress. Specifically, a chemical lattice strain was combined with the measured strain so that the calculated normal stress is forced to zero. The lattice parameter change caused by variation in solute content gives an equal shift in all three strain components. The combination of the chemical lattice parameter shift with the stress-induced strain gives the appearance of a compressive strain in the HAZ. The lattice parameter change derived from the above correction scheme is converted to an effective strain (dd/d). In Figure 6, this strain is compared to the corresponding chemical strains obtained from the d-spacings extrapolated from the $x$-ray measurements made on the same test panel.

The lattice parameter change was found to be equivalent to a 1 atomic percent change in copper solute content. 

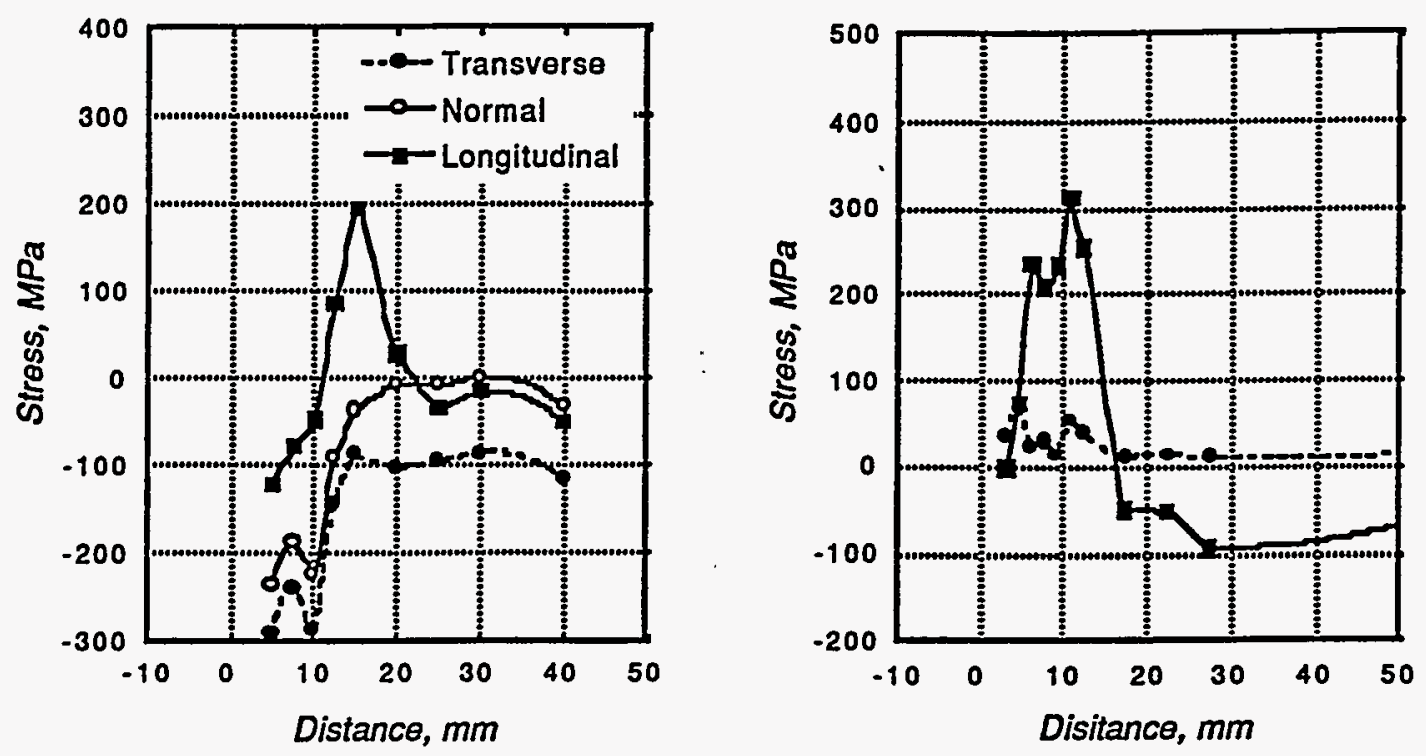

Figure 5. The discrepancy between $x$-ray (right) and neutron residual stress (left) determinations is concentrated in the HAZ.

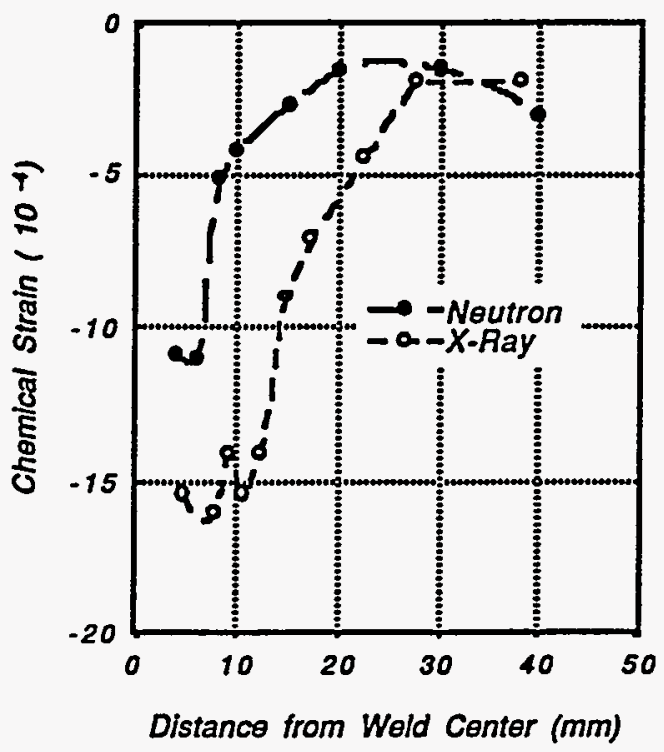

Figure 5. The strain correction derived from neutron measurements is compared with the direct determination of lattice parameter change obtained from $\mathrm{x}$-ray results. 
The longitudinal and transverse stresses obtained from the $x$-ray method and from the corrected neutron method are shown in Figure 7. The neutron transverse stresses are systematically compressive although small. The longitudinal stresses are in substantial agreement in the HAZ. Near the weld center the neutron stresses are more tensile and that suggests that the residual stresses at the center of the plate are more tensile than at the surface where the $\mathrm{x}$-ray measurement is made.

Longitudinal Stress

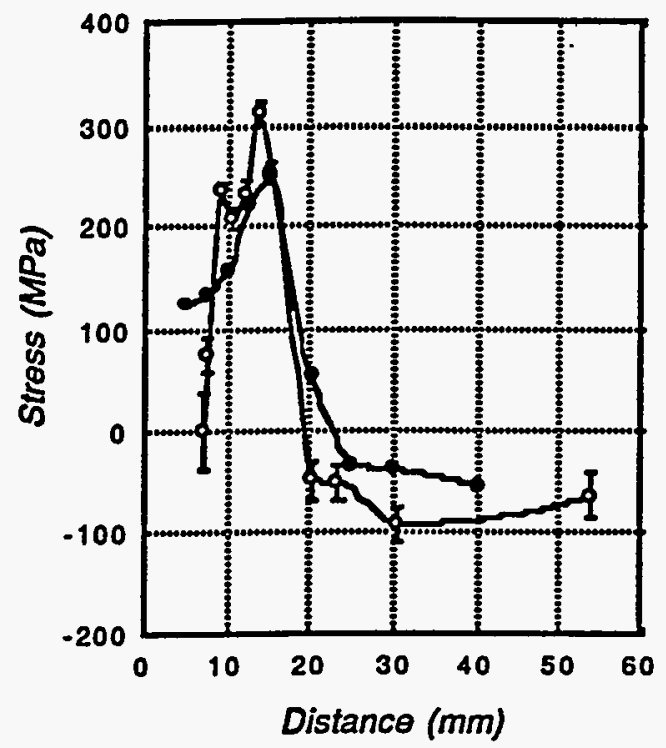

Transverse Stress

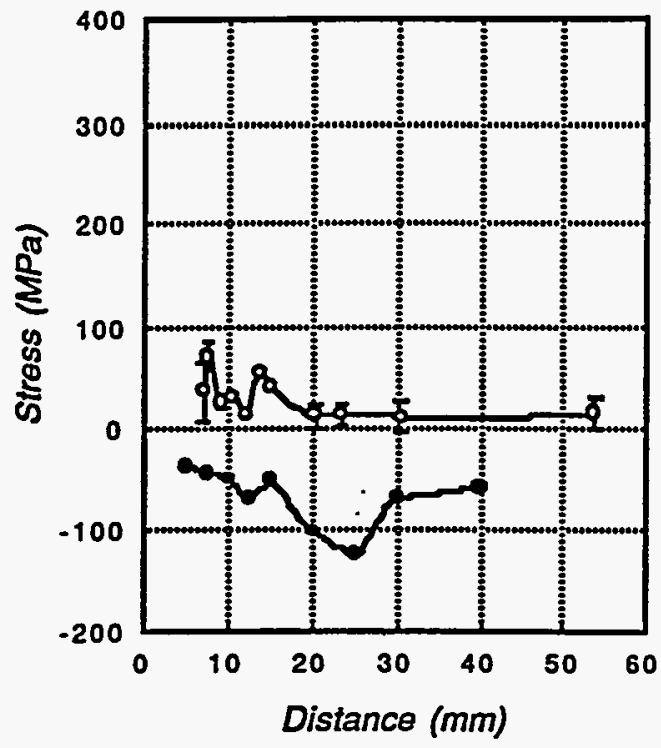

Figure 7. Corrected neutron stresses (closed) and x-ray stresses (open) are in substantial agreement for the longitudinal case but the neutron transverse stresses are systematically compressive.

\section{Acknowledgements}

* Managed by Lockheed Martin Energy Systems, under contract DE-AC05-84OR21400 for the U.S. Department of Energy. The authors thank Julian Bynum (NASA) and Lynda Johnston (Lockheed Martin Manned Space Systems) their support and interest in this project. We thank Stan David (ORNL) for his guidance on the welding technology and Linda Lowery (TEC) and Jack Wilson (TEC) for performing the x-ray measurements.

\section{References}

1. I. C. Noyan and J. B. Cohen, Residual Stress Measurement by Diffraction and Interpretation, Springer-Verlag, New York (1987)

2. J. H. Root, T. M. Holden, J. Schroeder, C. R. Hubbard, S. Spooner, T. A. Dodson and S. A. David, "Residual stress mapping in multipass ferritic steel weld", Mat. Sci. and Tech., 9 754-759 (1993).

3. A. Allen, C. Andreani, M. T. Hutchings, C. G. Windsor, "Measurement of internal stress within bulk materials using neutron diffraction", NDT International 14 249-254 (1981). 